\title{
Specific fluorogenic probes for ozone in biological and atmospheric samples
}

\author{
Amanda L. Garner ${ }^{1}$, Claudette M. St Croix ${ }^{2}$, Bruce R. Pitt ${ }^{2}$, George D. Leikauf ${ }^{2}$, Shin \\ Ando $^{1}$, and Kazunori Koide ${ }^{1, *}$ \\ ${ }^{1}$ Department of Chemistry, University of Pittsburgh, 219 Parkman Avenue, Pittsburgh, \\ Pennsylvania 15260, USA \\ ${ }^{2}$ Department of Environmental and Occupational Health, University of Pittsburgh, 100 Technology \\ Drive, Pittsburgh, Pennsylvania 15219, USA
}

\begin{abstract}
Ozone exposure is a growing global health problem, especially in urban areas. While ozone in the stratosphere protects the earth from harmful ultraviolet light, tropospheric or ground-level ozone is toxic and can damage the respiratory tract. It has recently been shown that ozone may be produced endogenously in inflammation and antibacterial responses of the immune system; however, these results have sparked controversy owing to the use of a non-specific colorimetric probe. Here we report the synthesis of fluorescent molecular probes able to unambiguously detect ozone in both biological and atmospheric samples. Unlike other ozone-detection methods, in which interference from different reactive oxygen species is often a problem, these probes are ozone specific. Such probes will prove useful for the study of ozone in environmental science and biology, and so possibly provide some insight into the role of ozone in cells.
\end{abstract}

The investigation of reactive oxygen species (ROS) has had a rather controversial history ${ }^{1}$. The existence of singlet oxygen and superoxide was first proposed in the late 1960s; however, because of the lack of sensitive and specific probes these results were met with scepticism, and these species were only confirmed in the late 1980s. Recently, ozone has been placed in the spotlight. It has been proposed that ozone is produced endogenously from singlet oxygen in both neutrophils and atherosclerotic plaque, which implicates ozone in inflammatory responses $2^{-} 4$. This conclusion was drawn from the premise that indigo carmine (1, Fig. 1) $)^{5}$ differentially reacted with ozone as opposed to other ROS. However, 1 has since been shown not only to react with ozone, but also with superoxide in a similar manner ${ }^{6}$, and thus challenges the proposal for endogenous ozone ${ }^{7-9}$. Despite the scepticism, a more recent report independently indicated the generation of ozone-like molecules in human neutrophils ${ }^{10}$.

Chemiluminescent methods, which include the use of $\mathbf{1}$, are also used to measure ozone in ambient air ${ }^{11,12}$, but other atmospheric compounds also absorb in this region of the

\footnotetext{
(C) 2010 Macmillan Publishers Limited. All rights reserved.

*Correspondence and requests for materials should be addressed to K.K., koide@ pitt.edu.

Author contributions

A.L.G., C.M.S., B.R.P, G.D.L. and K.K. designed the experiments. A.L.G. generated the data shown in Figs 2, 3 and 5. C.M.S. generated the data shown in Fig. 4. S.A. synthesized and characterized compound 8. A.L.G., C.M.S. and K.K. wrote the manuscript. Additional information

Supplementary information and chemical compound information accompany this paper at www.nature.com/naturechemistry. Reprints and permission information is available online at http://npg.nature.com/reprintsandpermissions/.
} 
electromagnetic spectrum and false-positive ozone readings are often reported ${ }^{13,14}$. In addition, many of these methods are sensitive to humidity. We reasoned that if a specific probe was available then ozone detection in air and biological systems would be achieved more reliably.

Several problems are associated with the use of $\mathbf{1}$ as a probe for ozone. First, the dye readily undergoes oxidative cleavage ${ }^{15}$, which is most likely responsible for the lack of specificity (Supplementary Fig. S2b). Additionally, the reaction of blue 1 with ROS yields 2 (Fig. 1), which is colourless and cannot be visualized directly without the use of a spectrometer, particularly in biological samples. Although $\mathbf{1}$ emits a characteristic chemiluminescence signal5 and absorbance maximum16, 17 (430 nm and $610 \mathrm{~nm}$, respectively), which have been used to measure ozone in atmospheric samples, biological samples are analysed using highperformance liquid chromatography (HPLC) or mass spectrometry in combination with these spectroscopic techniques to confirm the products because the signal for $\mathbf{2}$ (ultraviolet, $\lambda_{\max }=245$ and $298 \mathrm{~nm}$ ) overlaps with the signals for many other bioorganic compounds ${ }^{2,4,6}$. A similar approach has recently been reported for the simultaneous detection of ozone and carbonyls in air ${ }^{18}$. Although this system was shown to be resistant to humidity, it requires extensive extraction and derivatization prior to HPLC analysis, and its stability in the presence of other oxidizing agents was not reported.

Small molecule-based turn-on probes are particularly useful because their spectral properties are easily discernable and because they are compatible with aqueous media. Also, fluorescent samples can be visualized easily with the aid of a handheld fluorescence spectrometer, fluorescence microscope or even a simple laser pen. Although selective fluorescent probes exist for singlet oxygen19, superoxide19 and hydrogen peroxide20, previously no such probe has been reported for ozone (ozone probes adsorbed on solid surfaces used at present typically suffer from variability in temperature, pressure and humidity19). As such, we set out to design a fluorescent turn-on probe selective for ozone.

While compound 7 (Fig. 2) is as fluorescent as $2^{\prime}, 7^{\prime}$-dichlorofluorescein (DCF) ${ }^{21}$, when the phenolic hydroxy group is alkylated such compounds are nearly non-fluorescent $22^{-} 27$. Our hypothesis was that compound $\mathbf{4}$, which was also predicted to be nearly non-fluorescent, would react with ozone, and the resulting aldehyde $\mathbf{6}$ would undergo $\beta$-elimination to yield the fluorescent compound $\mathbf{7}$ and acrolein (Fig. 2). Hydrogen peroxide is also a by-product of this aqueous ozonolysis reaction, which could oxidatively stress cells 28 . Since non-toxic, physiological concentrations of hydrogen peroxide are between 10 and $100 \mu \mathrm{M}$ (ref. 29,30) and the amount of hydrogen peroxide produced is stoichiometric with respect to ozone, the level of this ROS should not reach the toxic, millimolar range concentrations that would inhibit catalase activity31. This terminal alkene probe should be specific for ozone because it contains an isolated (non-conjugated) olefin and should not yield a fluorescence signal on exposure to other ROS32,33 (Supplementary Fig. S2c). Based on this hypothesis, we designed and synthesized the homoallyl ether $\mathbf{4}$ in two steps from commercially available DCF in 64\% yield (Fig. 2) ${ }^{23}$. We then bubbled ozone through a solution of 4 in 95:5 acetone:water and the fluorescent compound 7 was obtained in quantitative yield, presumably through intermediates $\mathbf{5}$ and $\mathbf{6}$, and thus provided a positive indication for our probe design.

To develop a fluorescent method amenable to both biological and atmospheric detection, we chose a pH 7 buffer $\left(\mathrm{PO}_{4}{ }^{3-}=5 \mathrm{mM}\right)$ to perform the conversion of $\mathbf{4}$ into $\mathbf{7}$. A solution of 4 in $\mathrm{MeOH}$ and $\mathrm{pH} 7$ buffer (5:95) at $24^{\circ} \mathrm{C}$ was exposed to ozone and, after incubation at 37 ${ }^{\circ} \mathrm{C}$ for one hour to facilitate the conversion of 4 into 7 (see Supplementary Information for time-dependence data), 7 was observed (signal-to-background $(\mathrm{S} / \mathrm{B})=80$ ) (Fig. 3a). We envisaged that this detection method would be performed in the presence of cells, so we also 
carried out the ozonolysis reaction in a mixture of $10 \%$ fetile bovine serum in RPMI-1640 cell-culture media and $\mathrm{pH} 7$ buffer (1:3). Indeed, the method is compatible with components of the cell-culture media ( $\mathrm{S} / \mathrm{B}=104$; not shown), which indicates that this method should be amenable to in vitro and possibly in vivo studies. It is important to note that the conversion of $\mathbf{4}$ into $\mathbf{7}$ was found to be much faster in the presence of the components of cell-culture media and that the reaction was complete in 30 minutes (Supplementary Fig. S7).

Given our successful results with ozone, we next wanted to determine the specificity of our probe to ROS. No reaction or fluorescence signal was observed with the ROS examined (Fig. 3a), although fluorescence bleaching of $\mathbf{4}$ was observed when a large excess of these species was present. Hydrogen peroxide and the hydroxyl radical were also examined because the former is a byproduct of the aqueous ozonolysis reaction ${ }^{34}$, the latter is a product of ozone decomposition in aqueous solution ${ }^{11}$ and both are endogenous ROS. For each, no fluorescence-signal enhancement was observed (Fig. 3a). Thus, our probe generates fluorescence specifically with ozone and can be used to detect ozone even in the presence of other ROS. A similar set of experiments was also performed using 1 to demonstrate the lack of specificity and the turn-off nature of this colorimetric probe (see Fig. 1 and Supplementary Information).

We next examined the sensitivity of our fluorescent method for ozone detection. The fluorescence intensity correlated with the concentration of ozone in the $50 \mathrm{nM}-12.5 \mu \mathrm{M}$ (2.4-600 ppb) range with $\mathrm{S} / \mathrm{B}=2.6-310$ after tenfold dilution of the original samples ( 0 500 nM, Fig. 3b).

Ozone's role in damaging human tissues is unclear, so there is a need for a biomedical probe to better understand the localization of this highly reactive species. Cellular effects of ozone exposure have been observed; however, it is speculated that ozone is much too reactive to reach and permeate airway epithelial cells ${ }^{35-37}$. Thus, to examine the utility of our detection method in such biological samples, we first attempted ozone detection in the presence of various antioxidants found in the airway liquid lining. Ascorbic acid, glutathione and uric acid are the most predominant antioxidants present ${ }^{35-37}$ and, as Fig. 3c shows, our fluorescent method works in the presence of physiologically relevant antioxidants. We then proceeded to test our method with human pleural fluid to mimic the epithelial lining fluid of the lung. Indeed, a strong fluorescence signal was produced ( $\mathrm{S} / \mathrm{B}=92 ; \mathrm{Fig}$. 3d), which indicates that probe $\mathbf{4}$ should provide a tool to visualize indirectly this reactive gas in the study of ozone and the respiratory system.

As a further demonstration of the robustness of probe 4, we next examined the detection of ozone in human serum. As Fig. 3e shows, probe 4 is able to detect ozone even in the presence of other potentially reactive species in serum $(S / B=92)$. It is interesting that, although the maximum emission wavelength shifted to $531 \mathrm{~nm}$, the observed colour was blue. This observation proved to be general for this fluorophore scaffold, as both DCF and 7 behaved in a similar manner in serum. Although the exact reason for the red-shift is unclear at present, it is known that the emission spectra of fluoresceins can be influenced by various factors in serum ${ }^{38}$.

To determine whether our probe can be used in studies related to ozone's role in cell biology we incubated human bronchial epithelial cells with compound $\mathbf{4}$. Although compound $\mathbf{4}$ was cell permeable, it was found that it had been converted to a fluorescent compound inside the cells in the absence of external ozone within ten minutes. Based on our ongoing studies as to why compound $\mathbf{4}$ and structurally related compounds are not fluorescent, it was thought that the hydroxymethyl group of $\mathbf{4}$ may have been oxidized to give a more electron-withdrawing group, possibly a carboxy or aldehyde group, and so emit a strong fluorescence signal. To 
circumvent such an oxidation event, we prepared compound $\mathbf{8}$ and confirmed that this compound was also specific for ozone (see Supplementary Information for the details). As expected, this compound was nearly non-fluorescent and thus was used for the live-cell experiment. Unlike compound 4, compound 8 remained weakly fluorescent within the cells. Once a steady baseline signal had been established and maintained for five minutes, ozone gas was generated within the airtight environmental chamber that housed the cell-culture dishes, and fluorescence signals were monitored using live-cell microscopy for $\sim 15$ minutes. As Fig. 4 shows (see Supplementary Information for a film), a time-dependent increase in fluorescence emissions occurred inside the cells after ozone generation, which indicates that ozone can penetrate through cell membranes. These results show that further studies on the intracellular biological activity of ozone are warranted.

Detection in ambient indoor and outdoor air is also important because of the toxic effects of this gas ${ }^{39,40}$. Exposure to environmental ozone is particularly a problem for those who suffer from respiratory ailments, such as asthma, bronchitis and cystic fibrosis. These patients rely solely on community-based monitoring to adjust their behaviour so as to minimize their exposure. As such, one of our goals was to assess whether compound $\mathbf{4}$ could be used to develop a simple method by which ordinary citizens could monitor their total ozone exposure, and thus make more informed decisions about their outdoor activity. As a first step towards this goal, we carried out a proof-of-principle experiment. A solution of compound 4 (500 nmol) in dimethylsulfoxide (DMSO) was absorbed on a piece of adsorbent paper and allowed to dry; $\mathbf{1}$ was used for comparison because this is more amenable to continuous measurement than is a method based on ultraviolet absorbance. The paper strips were stored in an office room that had two photocopiers and two laser printers. After eight hours, the paper strips were removed and placed in a vial that contained $\mathrm{pH} 7$ buffer to elute the dyes. Figure 5a and the fluorescence emission of compound 7 (see Supplementary Information) show that $0.95 \mathrm{nmol}$ of $\mathbf{7}$ was generated, which indicates that at least $0.95 \mathrm{nmol}$ of ozone was exposed to the strip over eight hours. The paper strip that contained 1 displayed a 77\% decrease in absorbance at $610 \mathrm{~nm}$ (Fig. 5b), which correlates to the consumption of $387 \mathrm{nmol}$ of $\mathbf{1}$. The deviation in these values is presumably because of photobleaching and the lack of specificity of $\mathbf{1}$ towards various ROS, including singlet oxygen. Although the use of paper strips is not an optimal format, we envisage that a badge that contains probe $\mathbf{4}$ may be developed for patients to wear and so continuously measure their own total ozone exposure through the day.

We also wanted to examine ozone detection in ambient air. Solutions of 4 in $\mathrm{MeOH}$ and $\mathrm{pH}$ 7 buffer (5:95) were prepared and exposed to ambient air for eight hours on a sunny day $\left(\sim 32{ }^{\circ} \mathrm{C}\right)$ in various locations throughout Pittsburgh, Pennsylvania (data collected on 6 June 2008; for detailed locations, see Supplementary Information). Ozone detection was successful with S/B values of 10-17 (Fig. 5c), which correlates to 13-22 ppb in the probe solution exposed to the air. To ensure that we had selectively detected ozone, we screened a number of other pollutants (Fig. 5d). Nitrogen dioxide and sulfur dioxide are converted into their corresponding acids in aqueous solution, so nitric acid and sulfuric acid were screened. We also screened lead, palladium and platinum (known pollutants emitted from motor vehicles) at environmentally relevant concentrations ${ }^{41}$. None of these species produced a fluorescence signal. Aside from the specificity, it is important to note that because our detection method is performed in aqueous media it will not be affected by humidity. Thus, probe $\mathbf{4}$ may be used as a sensitive probe for ozone in the atmosphere.

In summary, we have developed specific and robust fluorescent probes for ozone. Our probes are able to fluorescently detect ozone in biological and environmental samples. Additional features include water compatibility and ease of measurement. Our probes should provide valuable tools with which to better understand ozone's role in human health and the 
atmosphere. Additionally, the simplicity of their use suggests that, after further optimizations (for example, acceleration of the conversion from $\mathbf{6}$ into $\mathbf{7}$ in buffer), it may be possible for individuals to monitor their exposure to ozone at home. This would be of enormous benefit to those who suffer from respiratory diseases, as they will be able to change their behaviour accordingly.

\section{Methods}

\section{Ozone detection}

Solutions of 4 (final concentration $12.5 \mu \mathrm{M}$ ) in a mixture of $\mathrm{MeOH}$ and $\mathrm{pH} 7$ buffer $\left(\left[\mathrm{PO}_{4}{ }^{3-}\right]=5 \mathrm{mM} ; 5: 95 ; 4.0 \mathrm{ml}\right)$ were prepared, and the samples were exposed to various amounts of ozone at $24{ }^{\circ} \mathrm{C}$ followed by incubation for one hour at $37{ }^{\circ} \mathrm{C}$ before fluorescence measurements (except in the ambient air experiments). The concentration of ozone was 5 $\mu \mathrm{M}$ for these studies. For experimental details with other ROS, see Supplementary Information. Fluorescence spectra were recorded in a disposable cuvette $(1 \times 1 \mathrm{~cm})$ on a Jobin Yvon FluoroMax-3 spectrometer under the control of a Windows-based PC using FluorEssence software. The samples were excited at $497 \mathrm{~nm}$ and the emission intensities were collected at $523 \mathrm{~nm}$. All spectra were corrected for emission intensity using the manufacturer-supplied photomultiplier curves.

\section{Ozone detection in indoor air}

One adsorbent paper (Kimwipe) was cut into two $11 \times 9 \mathrm{~cm}$ pieces. Compound 4 (DMSO solution, $500 \mathrm{nmol}$ total) was added to one portion of the Kimwipe and allowed to dry overnight in a laboratory drawer. The paper strip was then moved to a photocopy room that contained two photocopiers and two laser printers, and kept there for eight hours. The control remained in the laboratory drawer. After eight hours, the samples were placed into a scintillation vial and the dye was eluted with $\mathrm{pH} 7$ buffer $(6.0 \mathrm{ml}$; about five minutes) before fluorescence measurement.

\section{Ozone detection in ambient air}

Solutions of 4 (final concentration $12.5 \mu \mathrm{M}$ ) in a mixture of $\mathrm{MeOH}$ and $\mathrm{pH} 7$ buffer $\left(\left[\mathrm{PO}_{4}{ }^{3-}\right]=5 \mathrm{mM} ; 5: 95 ; 4.0 \mathrm{ml}\right)$ were prepared, and the samples were placed for eight hours in outdoor areas with heavy traffic. Care was taken to ensure the samples were not hit by direct sunlight. A negative control was prepared in the same manner, but incubated at $37^{\circ} \mathrm{C}$ in a closed vial for eight hours. After incubation for eight hours, the fluorescence of each sample was measured.

\section{Ozone detection in live human epithelial cells}

Human bronchial epithelial cells (BEAS-2B) (American Type Culture Collection) were grown in LHC-9 medium (Invitrogen) on glass-bottomed Petri dishes (MatTek) precoated with $0.01 \mathrm{mg} \mathrm{ml}^{-1}$ of human fibronectin (Invitrogen), $0.029 \mathrm{mg} \mathrm{ml}^{-1}$ Vitrogen 100 (Cohesion) and $0.01 \mathrm{mg} \mathrm{ml}^{-1}$ bovine serum albumin (Invitrogen) in LHC-9 medium ${ }^{42}$. Immediately prior to imaging, cells were rinsed with Hank's balanced salt solution, which contained calcium and magnesium, and placed inside a temperature-controlled, airtight environmental chamber and maintained at $37{ }^{\circ} \mathrm{C}$ and $5 \% \mathrm{CO}_{2}$ (Tokai Hit). Images were obtained using a Nikon TE2000E-PFS (Perfect Focus System) microscope equipped with a $40 \times$ oil-immersion objective (Nikon, CFI PlanFluor, NA 1.3) and, a fluorescein isothiocyanate longpass filter set (Chroma), a Q-Imaging SRV CCD camera (Q-Imaging) and MetaMorph software (Molecular Devices). The motorized XYZ stage used was made by ASI (Eugene). Baseline images were collected before the addition of $\mathbf{8}$ and time-lapse images obtained at 30 -second intervals after the addition of $\mathbf{8}(250 \mathrm{nM})$. Once a stable 
baseline had been achieved, multiple washes were carried out and the media replaced. The cells were then exposed to ozone ( 2.1 ppm) and monitored every 30 seconds for 15 minutes. Ozone was generated from medical grade oxygen (Valley Gas) via a model V1-0 ultraviolet ozonator (OREC) and analysed with a Dasibi (Glendale) direct-reading instrument. Ozone concentrations were maintained by adjusting both the intensity of the ultraviolet light and the flow rate of oxygen. For each experiment, images were collected from six stage positions, with a minimum of five cells per position (a minimum of 30 cells per experiment).

\section{Supplementary Material}

Refer to Web version on PubMed Central for supplementary material.

\section{Acknowledgments}

We acknowledge support from the US National Science Foundation (to K.K.) and the US National Institutes of Health (to C.M.S., B.R.P. and G.D.L). We thank Yang Gao for determining the specificity of compound $\mathbf{8}$ for ozone.

\section{References}

1. Smith LL. Oxygen, oxysterols, ouabain, and ozone: a cautionary tale. Free Radical Biol. Med 2004;37:318-324. [PubMed: 15223065]

2. Wentworth P Jr, et al. Evidence for antibody-catalyzed ozone formation in bacterial killing and inflammation. Science 2002;298:2195-2199. [PubMed: 12434011]

3. Babior BM, Takeuchi C, Ruedi JM, Gutierrez A, Wentworth P Jr. Investigating antibody-catalyzed ozone generation by human neutrophils. Proc. Natl Acad. Sci. USA 2003;100:3031-3034. [PubMed: 12601145]

4. Wentworth P Jr, et al. Evidence for ozone formation in human atherosclerotic arteries. Science 2003;302:1053-1056. [PubMed: 14605372]

5. Takeuchi K, Ibusuki T. Quantitative determination of aqueous-phase ozone by chemiluminescence using indigo-5,5'-disulfonate. Anal. Chem 1989;61:619-623. [PubMed: 2729594]

6. Kettle AJ, Clark BM, Winterbourn CC. Superoxide converts indigo carmine to isatin sulfonic acid. J. Biol. Chem 2004;279:18521-18525. [PubMed: 14978029]

7. Sies H. Ozone in arteriosclerotic plaques: searching for the 'smoking gun'. Angew. Chem. Int. Ed 2004;43:3514-3515.

8. Kettle AJ, Winterbourn CC. Do neutrophils produce ozone? BioFactors 2005;24:41-45. [PubMed: 16403962]

9. Pryor WA, et al. Free radical biology and medicine: it's a gas, man! Am. J. Physiol. Regul. Integr. Comp. Physiol 2006;291:R491-R511. [PubMed: 16627692]

10. Yamashita K, et al. Ozone production by amino acids contributes to killing of bacteria. Proc. Natl Acad. Sci. USA 2008;105:16912-16917. [PubMed: 18971328]

11. Horvath, M.; Bilitzky, L.; Huttner, J. Ozone. Elsevier; 1985.

12. Jimenez AM, Navas MJ, Galan G. Air analysis: determination of ozone by chemiluminescence. Appl. Spectrosc. Rev 1997;32:141-149.

13. Parrish DD, Fehsenfeld FC. Methods for gas-phase measurements of ozone, ozone precursors and aerosol precursors. Atmos. Environ 2000;34:1921-1957.

14. Williams EJ, et al. Comparison of ultraviolet absorbance, chemiluminescence, and DOAS instruments for ambient ozone monitoring. Environ. Sci. Technol 2006;40:5755-5762. [PubMed: 17007137]

15. Kuczkowski, RL. 1,3-Dipolar Cycloaddition Chemistry. John Wiley; 1984.

16. Maruo YY. Measurement of ambient ozone using newly developed porous glass sensor. Sens. Actuat., B 2007;126:485-491. 
17. Li J, Li Q, Dyke JV, Dasgupta PK. Atmospheric ozone measurement with an inexpensive and fully automated porous tube collector-colorimeter. Talanta 2008;74:958-964. [PubMed: 18371734]

18. Uchiyama S, Otsubo Y. Simultaneous determination of ozone and carbonyls using trans-1,2-bis(4pyridyl)ethylene as an ozone scrubber for 2,4-dinitrophenylhydrazine-impregnated silica cartridge. Anal. Chem 2003;80:3285-3290. [PubMed: 18341353]

19. Soh N. Recent advances in fluorescent probes for the detection of reactive oxygen species. Anal. Bioanal. Chem 2006;386:532-543. [PubMed: 16609844]

20. Miller EW, Tulyathan O, Isacoff EY, Chang CJ. Molecular imaging of hydrogen peroxide produced for cell signaling. Nature Chem. Biol 2007;3:263-267. [PubMed: 17401379]

21. Koide K, et al. Scalable and concise synthesis of dichlorofluorescein derivatives displaying tissue permeation in live zebrafish embryos. ChemBioChem 2008;9:214-218. [PubMed: 18161734]

22. Song F, Watanabe S, Floreancig PE, Koide K. Oxidation-resistant fluorogenic probe for mercury based on alkyne oxymercuration. J. Am. Chem. Soc 2008;130:16460-16461. [PubMed: 19049443]

23. Song F, Garner AL, Koide K. A highly sensitive fluorescent sensor for palladium based on the allylic oxidative insertion mechanism. J. Am. Chem. Soc 2007;129:12354-12355. [PubMed: 17887672]

24. Garner AL, Koide K. Oxidation state-specific fluorescent method for palladium(II) and platinum(IV) based on the catalyzed aromatic Claisen rearrangement. J. Am. Chem. Soc 2008;130:16472-16473. [PubMed: 19554719]

25. Garner AL, Koide K. Fluorescent method for platinum detection in buffers and serums for cancer medicine and occupational hazards. Chem. Commun 2009:83-85.

26. Garner AL, Koide K. Studies of a fluorogenic probe for palladium and platinum leading to a palladium-specific detection method. Chem. Commun 2009:86-88.

27. Garner AL, Song F, Koide K. Enhancement of a catalysis-based fluorometric detection method for palladium through rational fine-tuning of the palladium species. J. Am. Chem. Soc 2009;131:5163-5171. [PubMed: 19317401]

28. Chang MCY, Pralle A, Isacoff EY, Chang CJ. A selective, cell-permeable optical probe for hydrogen peroxide in living cells. J. Am. Chem. Soc 2004;126:15392-15393. [PubMed: 15563161]

29. Mueller S, Riedel H-D, Stremmel W. Determination of catalase activity at physiological hydrogen peroxide concentrations. Anal. Biochem 1997;245:55-60. [PubMed: 9025968]

30. Imlay JA. Cellular defenses against superoxide and hydrogen peroxide. Annu. Rev. Biochem 2008;77:755-776. [PubMed: 18173371]

31. Deisseroth A, Dounce AL. Catalase: physical and chemical properties, mechanism of catalysis, and physiological role. Physiol. Rev 1970;50:319-375. [PubMed: 4912904]

32. Clennan EL, Pace A. Advances in singlet oxygen chemistry. Tetrahedron 2005;61:6665-6691.

33. Sawyer DT, Valentine JS. How super is superoxide? Acc. Chem. Res 1981;14:393-400.

34. Bailey, PS. Ozonation in Organic Chemistry: Olefinic Compounds. Academic Press; 1978.

35. Pryor WA. How far does ozone penetrate into the pulmonary air/tissue boundary before it reacts? Free Radical Biol. Med 1992;12:83-88. [PubMed: 1537573]

36. Pryor WA. Mechanisms of radical formation from reactions of ozone with target molecules in the lung. Free Radical Biol. Med 1994;17:451-464. [PubMed: 7835752]

37. Mudway IS, Kelly FJ. Ozone and the lung: a sensitive issue. Mol. Aspects Med 2000;21:1-48. [PubMed: 10804262]

38. Soini E, Hemmila I. Fluoroimmunoassay: present status and key problems. Clin. Chem 1979;25:353-361. [PubMed: 400437]

39. Weschler CJ. Ozone's impact on public health: contributions from indoor exposures to ozone and products of ozone-initiated chemistry. Environ. Health Perspect 2006;114:1489-1496. [PubMed: 17035131]

40. Weschler CJ. Ozone in indoor environments: concentration and chemistry. Indoor Air 2000;10:269-288. [PubMed: 11089331] 
41. Ely JC, et al. Implications of platinum-group element accumulation along U.S. roads from catalytic-converter attrition. Environ. Sci. Technol 2001;35:3816-3822. [PubMed: 11642438]

42. Nemec AA, Leikauf GD, Pitt BR, Wasserloos KJ, Barchowsky A. Nickel mobilizes intracellular zinc to induce metallothionein in human airway epithelial cells. Am. J. Resp. Cell Mol. Biol. 2009 doi:10.1165/rcmb.2008-04090C. 


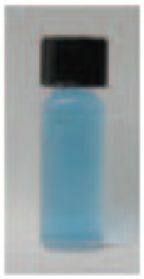<smiles>O=C1/C(=C2\Nc3ccc(S(=O)(=O)O)cc3C2=O)Nc2ccc(S(=O)(=O)O)cc21</smiles>

Blue<smiles>[R6]S(=O)(=O)CC</smiles>

2

Colourless

Figure 1. Indigo carmine (1) is a non-selective, colorimetric probe for ROS In this case, a blue solution of $\mathbf{1}$ reacts with various ROS to form colourless isatin sulfonic acid (2). 
<smiles>[R]Oc1cc2oc3cc(=O)c(Cl)cc-3c(-c3ccccc3C(=O)O)c2cc1Cl</smiles>

DCF: $\mathrm{R}=\mathrm{H}$

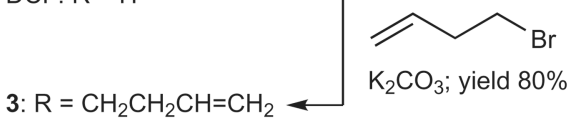<smiles>C=CCCOc1cc2oc3cc(=O)c(Cl)cc-3c(-c3ccccc3CO)c2cc1Cl</smiles>

4

Non-fluorescent<smiles></smiles>

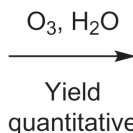
quantitative

$$
\mathrm{HCHO}+\mathrm{H}_{2} \mathrm{O}_{2}
$$$$
\mathrm{H}_{2} \mathrm{O}
$$<smiles>O=c1cc2oc3cc(Cl)c(Cl)cc3c(-c3ccccc3CO)c-2cc1Cl</smiles>

7

Fluorescent<smiles>C=CC(=O)CCCC</smiles><smiles>O=c1cc2oc3cc(OCCC4COOO4)c(Cl)cc3c(-c3ccccc3CO)c-2cc1Cl</smiles><smiles>CCC(C)=[O+][O-]</smiles><smiles>O=CCCOc1cc2oc3cc(=O)c(Cl)cc-3c(-c3ccccc3CO)c2cc1Cl</smiles>

Figure 2. Synthesis and mechanistic design of ozone probe 4

Probe $\mathbf{4}$ was prepared in two steps from DCF. The terminal olefin of $\mathbf{4}$ reacts with ozone to form molozonide 5 via a $(3+2)$ cycloaddition, which undergoes retro $(3+2)$ cycloaddition to form aldeyde $\mathbf{6}, \mathrm{HCHO}$ and $\mathrm{H}_{2} \mathrm{O}_{2}$. Aldehyde 6 then undergoes $\beta$-elimination to form the fluorescent compound $\mathbf{7}$ and $\mathrm{CH}_{2}=\mathrm{CHCHO}$. DIBALH=diisobutylaluminium hydride, $\mathrm{DDQ}=2,3$-dichloro-5,6-dicyanobenzoquinone. 

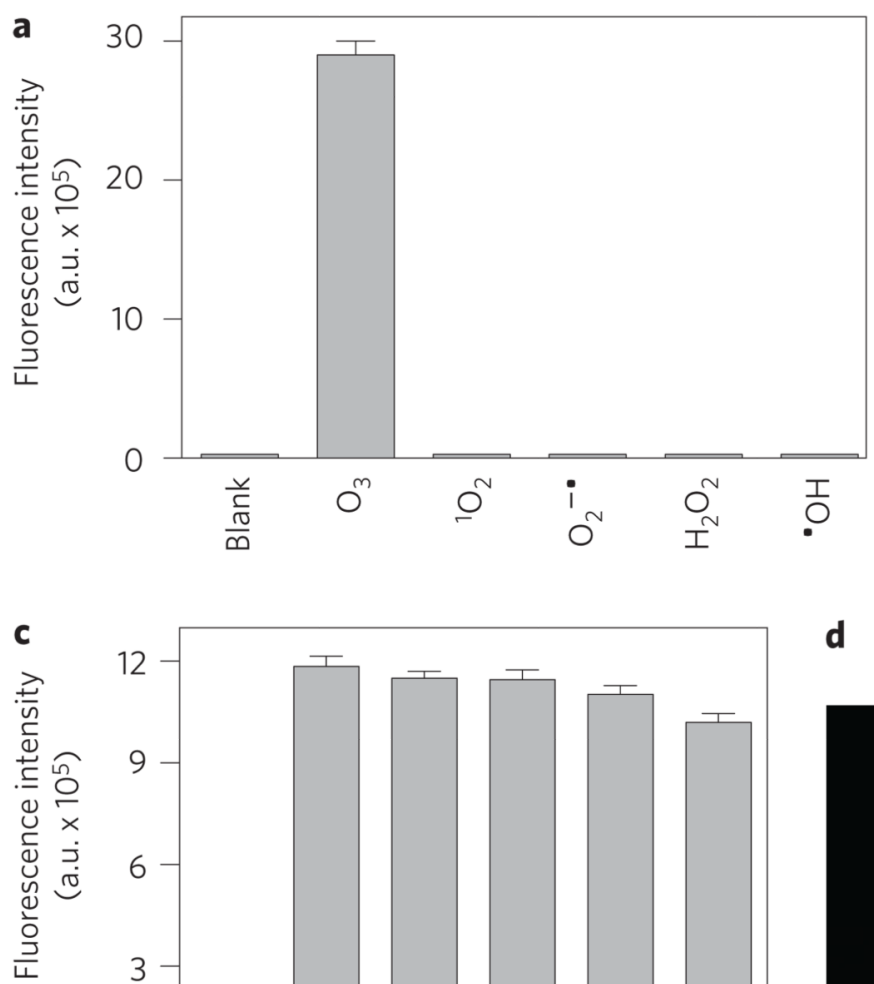

d
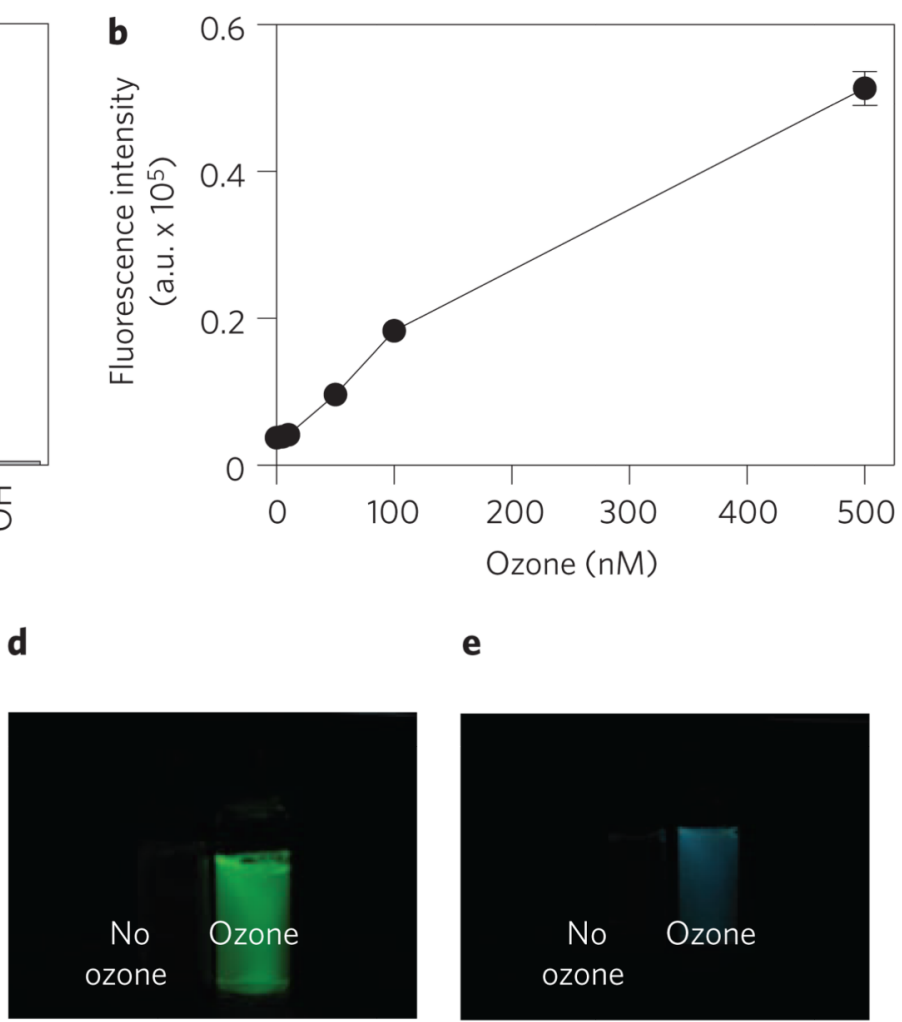

e

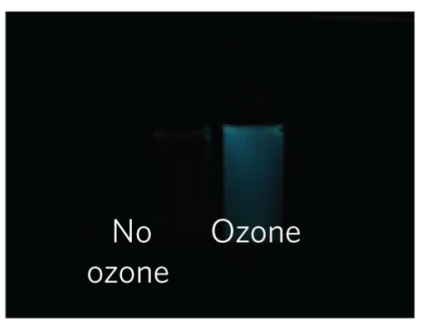

Figure 3. Ozone detection in aqueous and biological media

Experimental details are given in the Methods section. Each experiment was performed in triplicate and error bars were determined from the mean and standard deviation (Prism 5.0a, GraphPad Software). a, ROS specificity. b, Correlation between fluorescence intensity and ozone concentration in $\mathrm{MeOH}$ and $\mathrm{pH} 7$ buffer (5:95) after tenfold dilution of the original samples. The intensity was linear up to $12.5 \mu \mathrm{M}$ (see Supplementary Information). c, Ozone detection in the presence of antioxidants. In all cases, the concentration of ascorbic acid was $50 \mu \mathrm{M}$ and concentration of glutathione and uric acid were $100 \mu \mathrm{M}$. d, Ozone detection in human pleural fluid and pH 7 buffer (1:3) visualized under a long-range ultraviolet lamp. e, Ozone detection in human serum and $\mathrm{pH} 7$ buffer (1:3) visualized under a long-range ultraviolet lamp. 

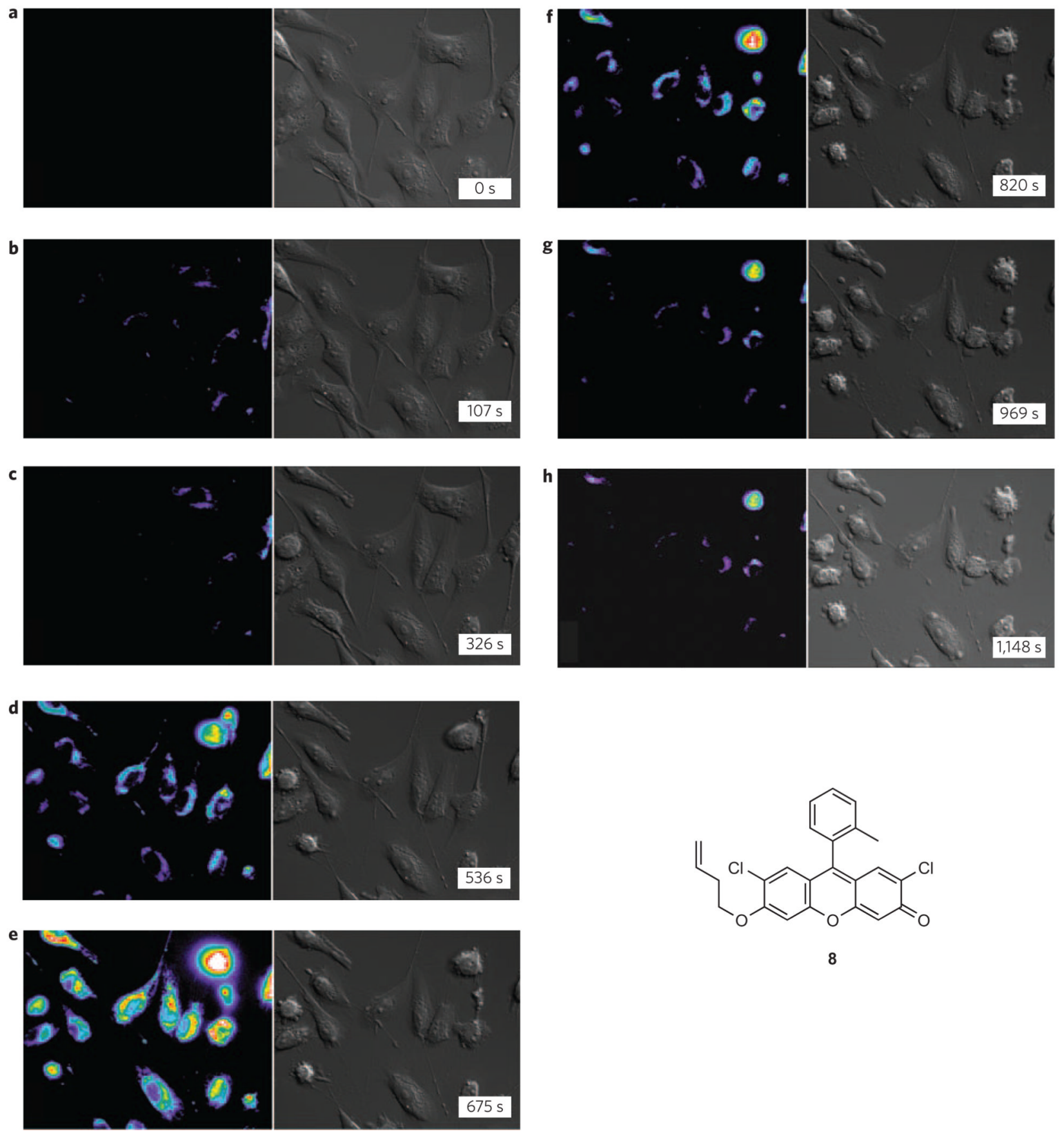

8

Figure 4. Live-cell imaging of human bronchial epithelial cells in the presence of ozone using compound 8

a-h The left-hand panels are pseudocolour images that indicate the changes in emission intensity over time, and the right-hand panels show differential interference contrast images of the bronchial epithelial cells. a, Before the addition of $\mathbf{8}(0 \mathrm{~s})$. b. At $107 \mathrm{~s}$ a steady-state intensity was reached with compound 8 at $250 \mathrm{nM}$. c, At $326 \mathrm{~s}$ an ozone flow started. d, At $536 \mathrm{~s}$ the emission intensity increased. e, At $675 \mathrm{~s}$ the emission maximum was reached. f, At 820 s cells started to die. $\mathbf{g}$, At $969 \mathrm{~s}$ the emission continued to fall. h, At 1,148 s the ozone flow stopped. 

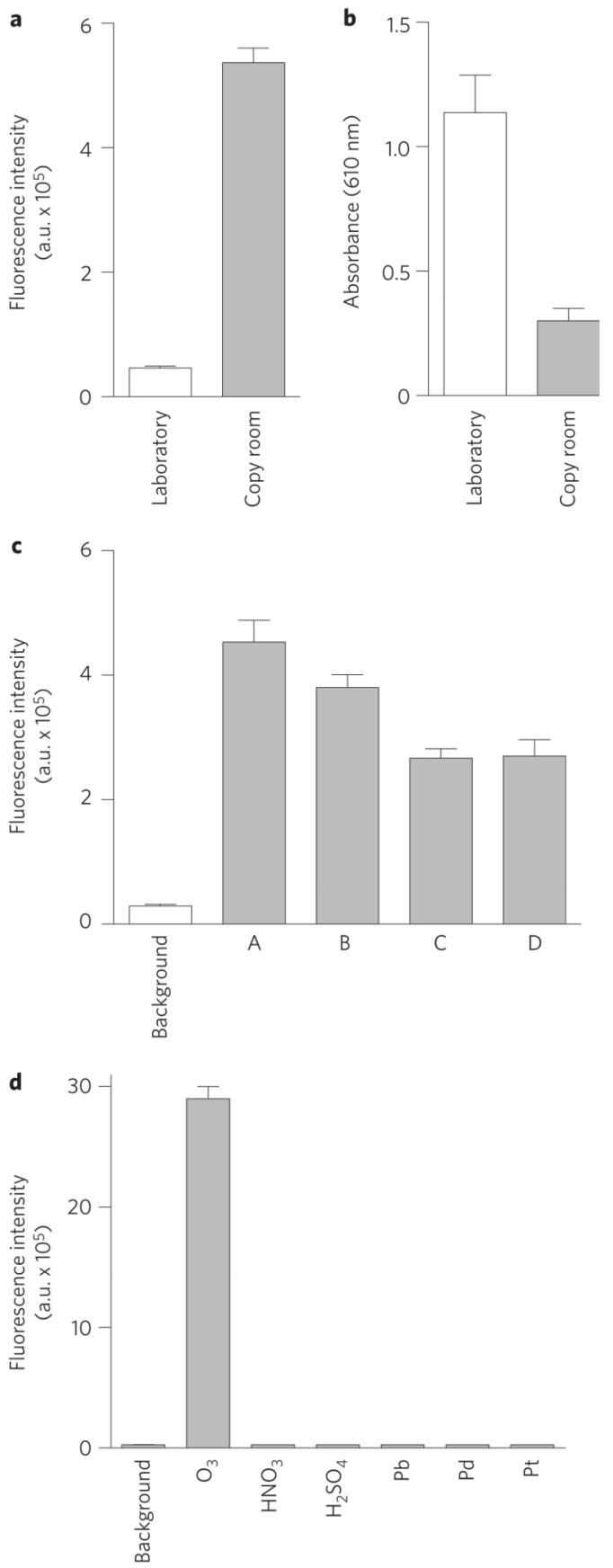

Figure 5. Conversion of 4 into 7 enables the detection of ozone in air samples a,b, Dyes $(500 \mathrm{nmol}) \mathbf{4}(\mathbf{a})$ and $\mathbf{1}(\mathbf{b})$ were absorbed onto pieces $(11 \times 9 \mathrm{~cm})$ of adsorbent paper and used to detect ozone in indoor air for eight hours. c,d, Solutions of $4(12.5 \mu \mathrm{M})$ in $\mathrm{MeOH}$ and $\mathrm{pH} 7$ buffer (5:95) were exposed to ambient air in various locations (A-D) throughout a city and ozone assays performed. Ozone was measured in outdoor air for eight hours (c), as was its specificity against other air pollutants (d) (acid concentration, $250 \mu \mathrm{M}$; metal concentration, $100 \mathrm{nM}$ ). Experiments were performed in triplicate and error bars were determined from the mean and standard deviation (Prism 5.0a, GraphPad Software). For experimental details, see Supplementary Information. 